\title{
Time is your best friend, but it soon becomes your worst enemy: The conflict of venoarterial extracorporeal membrane oxygenation in cardiac surgery
}

\author{
Michele Di Mauro, $\mathrm{MD}, \mathrm{PhD},{ }^{\mathrm{a}}$ and Roberto Lorusso, $\mathrm{MD}, \mathrm{PhD}^{\mathrm{b}}$
}

\footnotetext{
From the ${ }^{\mathrm{a}}$ Department of Cardiovascular Disease, University of L'Aquila, L'Aquila, Italy; and ${ }^{\mathrm{b}}$ Cardio-Thoracic Surgery Department, Heart \& Vascular Centre, Maastricht University Medical Centre, Maastricht, The Netherlands.

Disclosures: Authors have nothing to disclose with regard to commercial support.

Received for publication Dec 27, 2017; revisions received Jan 3, 2018; accepted for publication Jan 18, 2018; available ahead of print March 14, 2018.

Address for reprints: Michele Di Mauro, MD, PhD, University of L'Aquila, Department of Cardiovascular Disease, Piazza Tommasi 1, L'Aquila 67100, Italy (E-mail: mdimauro1973@gmail.com).

J Thorac Cardiovasc Surg 2018; 155:2477-8

$0022-5223 / \$ 36.00$

Copyright (C) 2018 by The American Association for Thoracic Surgery

https://doi.org/10.1016/j.jtcvs.2018.01.033
}

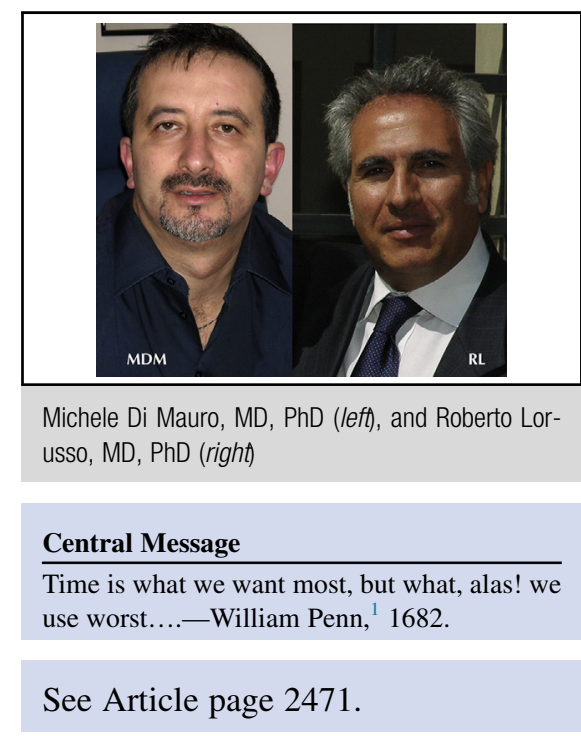

The study of Distelmaier and colleagues ${ }^{2}$ in this issue of the Journal has several relevant strengths that are worth underlining. First, their series is one of the largest experiences in the postcardiotomy venoarterial (VA) extracorporeal membrane oxygenation (ECMO) setting. Second, the in-hospital outcome shown in their study is rather favorable, with almost $40 \%$ of the patients surviving to hospital discharge, comparing favorably with global experience. ${ }^{3}$ Third, they have provided a time-related predictive value, ECMO duration of 7 days, as a practical yet paramount threshold to indicate a sort of point of no return regarding hope for patient survival and recovery. Fourth, ECMO duration affected not only early outcome but also postdischarge prognosis, including patients subsequently undergoing heart transplant (HTx) or ventricular assist device (VAD) implantation.

\section{VA-ECMO DURATION}

The predictive value of ECMO duration has been recently highlighted by Smith and coworkers in their Extracorporeal Life Support Organization (ELSO) registry analysis of almost 2700 patients submitted to VA-ECMO. ${ }^{4}$ That study showed that best survival was observed with VA-ECMO weaning at the fourth day of support. ${ }^{4}$ A shorter duration was associated with higher mortality, most likely because of unsuccessful support, and a gradually decreasing survival from 4 to 12 days of assistance was also observed, with a constant low survival beyond the second week of cardiorespiratory support. ${ }^{4}$ Why is such a time limit so important in ECMO? Can time on support be used for prognosis in postcardiotomy ECMO? ECMO duration, unfortunately, is strictly linked to increasing rate of complications, particularly in the cardiac surgical setting. ${ }^{5}$ This aspect is paramount to understanding that ECMO results in cardiac surgical patients may be less satisfactory than in other cardiovascular fields. ${ }^{6}$ For the time being, according to current

knowledge and understanding of ECMO, the duration of ECMO support to achieve myocardial and peripheral organ recovery should not exceed 12 days from implantation, with awareness that early failure may occur and that lack of recovery and increased rate of complications affecting patient survival will invariably and gradually occur after the first week of support.

\section{VA-ECMO IN CARDIAC SURGICAL PATIENTS}

VA-ECMO is increasingly used for cardiorespiratory support in patients affected by refractory cardiogenic shock or cardiac arrest after cardiac surgery. ${ }^{3}$ Such an expanded use, however, has not been associated with an improved early outcome. Indeed, a trend toward worse survival rates, reaching a disappointing $15 \%$ of in-hospital survival in the most recent series, has been recently described through another analysis of the Extracorporeal Life Support Organization registry. ${ }^{3}$ Cardiac surgical patients are usually characterized by substantial pre-ECMO comorbidities and more advanced age. ${ }^{7}$ All these factors, individually or in association, may influence the capability of the myocardium to recover or hamper favorable body response to prolonged extracorporeal mechanical assistance. In some patients, the mechanical support does not prompt to improved cardiac function or organ integrity, and clinicians may therefore be forced to bridge the patient toward more advanced treatments, such as HTx or long-lasting VADs. The important 
message of this study is that prolonged VA-ECMO duration, namely longer than 7 days, in cardiac surgical patients is associated with a disproportionate mortality at early and later stages. As such, lack of cardiac improvement at this time limit may indicate futile support. These findings suggest that HTx or VADs in such ECMO-supported patients should be used earlier, whereas ECMO withdrawal for a most likely hopeless mechanical cardiocirculatory assistance in patients without signs of recovery should be also considered if no other option available or feasible. This issue may have an even more important role in centers that do not perform HTx or VAD implantation, because patient transfer to an appropriate institution should be activated and realized in time to prevent life-threatening complications or to improve post-HTx or post-VAD results.

\section{VA-ECMO MANAGEMENT AND WEANING}

The weaning modality and timing are obviously of great importance during the ECMO course, but there may be additional factors not discussed or underlined by Distelmaier and colleagues ${ }^{2}$ in their study. The cardiac conditions at ECMO implantation or during support, particularly in terms of left ventricular dilatation and stasis, have been recently underlined as among the most important aspects in terms of likelihood and timing of myocardial recovery during ECMO support. ${ }^{8}$ The use of left ventricular venting during ECMO with various methods is still applied on a limited basis ${ }^{9}$; however, this aspect was not clearly addressed by the Vienna group in their series. ${ }^{2}$ Although whether the application of left ventricular venting plays a substantial role in the likelihood and time of ECMO weaning is still a controversial issue, some evidence seems to suggest that this is the case, although more compelling proofs are still needed. Is a more structured and multitasking support (improved circulation and oxygenation, while achieving an effective cardiac unloading during ECMO support) thus going to affect patient outcome, management, and decision making in the future? As mentioned, several clues indicate that simple strategy in ECMO management might be revised in the future to achieve better results. ${ }^{8}$

\section{CLINICIAN AND PATIENT'S FAMILY}

The aspects mentioned here deserve additional emphasis also in the relationship between the clinician and the patient's relatives. Discussion about alternatives or further options (limited) or about the possibility of a difficult decision (ECMO withdrawal) are needed as soon as ECMO implantation is contemplated in the patient's perioperative course, particularly in institutions that are not transplant centers. ${ }^{3}$

\section{References}

1. Penn W. Some Fruits of Solitude, in Reflections and Maxims, Relating to the Conduct of Human Life: In Two Parts. 7th ed. London: J Sowle; 1718.

2. Distelmaier K, Wiedemann D, Binder C, Haberl T, Zimpfer D, Heinz G, et al. Duration of extracorporeal membrane oxygenation support and survival in cardiovascular surgery patients. J Thorac Cardiovasc Surg. 2018;155:2471-6.

3. Whitman G. Extracorporeal membrane oxygenation for the treatment of postcardiotomy shock. J Thorac Cardiovasc Surg. 2017;153:95-101.

4. Smith M, Vukomanovic A, Brodie D, Thiagarajan R, Rycus P, Buscher H. Duration of veno-arterial extracorporeal life support (VA ECMO) support and outcome: an analysis of the Extracorporeal Life Support Organization (ELSO) registry. Crit Care. 2017;21:45.

5. Rastan AJ, Dege A, Mohr M, Doll N, Falk V, Walther T, et al. Early and late outcomes of 517 consecutive adult patients treated with extracorporeal membrane oxygenation for refractory postcardiotomy cardiogenic shock. J Thorac Cardiovasc Surg. 2010;139:302-11. 311.e1.

6. Lorusso R, Centofanti P, Gelsomino S, Barili F, Di Mauro M, Orlando P, et al; GIROC Investigators. Venoarterial extracorporeal membrane oxygenation for acute fulminant myocarditis in adult patients: a 5-year multi-institutional experience. Ann Thorac Surg. 2016;101:919-26.

7. Lorusso R, Gelsomino S, Parise O, Mendiratta P, Prodhan P, Rycus P, et al. Venoarterial extracorporeal membrane oxygenation for refractory cardiogenic shock in elderly patients: trends in application and outcome from the extracorporeal life support organization (ELSO) registry. Ann Thorac Surg. 2017;104:62-9.

8. Pappalardo F, Schulte C, Pieri M, Schrage B, Contri R, Soeffker G, et al. Concomitant implantation of Impella ${ }^{\circ}$ on top of veno-arterial extracorporeal membrane oxygenation may improve survival of patients with cardiogenic shock. Eur J Heart Fail. 2017;19:404-12.

9. Meani P, Gelsomino S, Natour E, Johnson DM, Rocca HB, Pappalardo F, et al. Modalities and effects of left ventricular unloading extracorporeal life support: a review of the current literature. Eur J Heart Fail. 2017;19(Suppl 2):84-91. 